\title{
Changes in hip and ankle range of motion and hip muscle strength in 8-11 year old novice female ballet dancers and controls: a 12 month follow up study
}

\author{
K L Bennell, K M Khan, B L Matthews, C Singleton
}

\begin{abstract}
Objectives-To evaluate in a 12 month longitudinal study changes in hip and ankle range of motion and hip muscle strength in young female novice ballet dancers.

Methods-Fifty three of the original 77 (69\%) female dancers aged 8-11 years and 40 of the original $49(82 \%)$ controls returned for follow up measurements one year later. Supine right active hip external (ER) and internal (IR) rotation were measured using an inclinometer. A turnout protractor was used to assess standing active turnout range. Range of right weight bearing ankle dorsiflexion and calf muscle length were measured in a standing lunge position using an inclinometer. A manual muscle tester was used to assess right hip flexor, IR, ER, abductor and
\end{abstract} adductor strength.

Results-The mean (SD) 12 month change in hip ER did not differ between dancers $\left(11.7(11.3)^{\circ}\right)$ and controls (8.1 $\left.(17.6)^{\circ}\right)$. Dancers gained $12.5(13.5)^{\circ}$ hip IR which was significantly greater than controls $\left(0.5(13.9)^{\circ}\right)$. Greater IR change was associated with improved IR strength $(r=0.34, p<0.001)$. Dancers increased total turnout $\left(12.0(16.7)^{\circ}\right)$ significantly more than controls $\left(2.2(20.0)^{\circ}\right)$. There was no significant change in ankle dorsiflexion range in either group. Dancers and controls increased in all measures of hip muscle strength $(p<0.001)$ and dancers achieved significantly greater gains in three out of five muscle groups (all, p<0.05).

Conclusions-Total hip range of motion increased in both ballet students and controls at this young age. However, ankle dorsiflexion did not, which is probably due to this movement being blocked by bony apposition, rather than soft tissue stretch. This has implications for ballet teachers, as it has long been accepted that this movement could be improved with training. Dancers had greater increases in hip strength after 12 months compared with controls in muscles specific for ballet, suggesting that hip strength can be trained at this young age. Whether these gains are permanent requires further study.

(Br F Sports Med 2001;35:54-59)
Keywords: dance; ballet; range of motion; muscle strength

Among the many physical attributes demanded of elite female ballet dancers, none is more important than hip external rotation (ER) as this is fundamental to the turned out position characteristic of the art. ${ }^{1}$ In addition, it has often been stated that dancers must have a large degree of ankle dorsiflexion (DF) to adopt the position of plié and to jump well. ${ }^{2}{ }^{3}$ Despite requiring muscle strength for jumps and balance on one leg, dancers are reported to have limb strength that is lower than in physically active participants in other sports. ${ }^{4}$

An intriguing question is are these exceptional artist-athletes born or made? Cross sectional descriptions of athlete-control differences do not shed any light on causality, as differences may be merely due to self selection. Nevertheless, ballet studios the world over are filled with young dancers enthusiastically (and not!) striving to increase their hip ER, ankle $\mathrm{DF}$, and lower limb strength at the exhortation of their well meaning ballet teachers. Unfortunately there are, as yet, no published studies describing longitudinal change in ballet specific range of motion and strength, so these endeavours may be in vain. Furthermore, there is evidence that attempts at excessively forcing range of motion can be associated with injuries. $^{256}$

Therefore, we studied functional hip ER, ankle DF, and hip muscle strength in prepubertal and peripubertal novice female ballet dancers and controls at baseline and at 12 months follow up. The baseline data have been reported previously. ${ }^{7}$ The specific aim of the present study was to determine whether balletic training led to change in any of these variables relative to non-dancing controls. If our study proved that certain physical attributes were not amenable to change with training, this would have significant implications for the curriculum in ballet schools and for selection of dancers into elite programmes.

\section{Materials and methods}

STUDY DESIGN

The study design was a 12 month longitudinal follow up.

SUBJECTS

Fifty three of the original 77 (69\%) female ballet dancers (8.0-11.1 years old) who partici- 
Table 1 Description of dance training in dancers

\begin{tabular}{ll}
\hline Dancing characteristics & Mean (SD) \\
\hline Age started dancing classes (years) & $4.2(1.3)$ \\
Weekly hours danced in last 12 months & $4.6(2.0)$ \\
Classical & $3.0(1.6)$ \\
Tap & $1.0(0.5)$ \\
Character & $0.8(0.3)$ \\
Modern & $1.3(0.7)$ \\
Other & $1.0(0.5)$ \\
Started pointe & $8(15)$ \\
\hline
\end{tabular}

^Given as number (\%).

pated in the baseline study returned for follow up measurements 12 months later. The remainder were still attending ballet classes but were unavailable for testing at the time. The dancers were originally recruited from classical ballet schools throughout Melbourne. During the 12 month study they participated in a range of weekly hours of ballet training from 1 to 10.3 hours. Table 1 presents descriptive data on dance training over the 12 month study period.

The control cohort consisted of 40 of the original $49(82 \%)$ non-dancing girls (8.3-11.1 years old). Controls had to participate in less than two hours a week of extracurricular sporting activities (excluding swimming) and have done less than three months of balletic or gymnastic training. They were originally recruited from 63 metropolitan primary schools throughout Melbourne, Australia. The controls were matched by age and residential postcode to obtain similar socioeconomic distributions to the dancers.

To be included in the study, all subjects had to be Tanner stage 1 (prepubertal) or 2 (peripubertal) at baseline as defined by self reported Tanner breast staging. ${ }^{8}$ Controls were excluded if they had a body mass index greater than 22.4. This was based on the maximum body mass index of dancers in a pilot study. Table 2 summarises the descriptive data for both dancers and controls for the baseline and 12 month visits.

The study was approved by the University of Melbourne human research ethics committee and the Royal Melbourne Hospital board of medical research. Written informed consent was provided by a parent/guardian of all subjects.

\section{MEASUREMENT PROTOCOLS}

Right sided hip ER and internal rotation (IR) range, turnout angle, ankle DF range, calf muscle length, and hip muscle strength were measured in all dancers and controls by one of four raters, all specifically trained in measurement procedures. The same rater tested all variables in the same subject. These procedures have been detailed previously. ${ }^{7}$ No warm up was performed before testing although practice trials were given for each test.

Hip ER and IR range

An inclinometer (Isomed, Portland, Oregon, USA) was used to measure range of active hip ER and IR in the right hip. The subject was positioned supine with the right thigh stabilised in a $U$ tube with the knee bent and the lower leg hanging freely over the edge of a table. The long axis of the inclinometer was placed along the anterolateral margin of the tibia, $12 \mathrm{~cm}$ below the tibial tuberosity. The angle from vertical was measured to the nearest degree at the limit of hip ER and IR. The median of three tests was recorded for analysis.

Standing turnout in first position

A specially constructed turnout protractor was used to measure the range of motion obtained in the turnout position. The turnout protractor displayed rays from $10^{\circ}$ to $100^{\circ}$, bilaterally, marked in $1^{\circ}$ intervals on each side of the central spine. Subjects began by standing on the device with their heels against the $5 \mathrm{~cm}$ central spine. The landmark used for measurement was the web space between the second and third toes. Subjects were asked to perform maximal bilateral turnout in one sweep, with the movement coming from the hips. To quantify turnout, the difference between the angle of the foot in the neutral position and the angle in the turned out position was measured on both the right and left sides. Subjects made five attempts at turnout and the median was used for analysis.

\section{Ankle passive DF range (standing plié in parallel)}

To measure the range of passive ankle DF on the right, subjects stood facing a wall in a stepstance position with the feet approximately shoulder width apart. They stood on a $15^{\circ}$ wedge to standardise the amount of foot supination/pronation. They were instructed to lunge forward by approximating the front knee (right) to the wall while keeping the right heel in contact with the ground. The wedge was gradually moved away from the wall until the maximum distance that the subject could lunge and still touch the wall with their front knee was reached. At this point DF was measured by aligning the long axis of the inclinometer with the midline of the right Achilles tendon. Subjects performed three trials of each DF measure and the median was used for analysis.

\section{Calf muscle length}

Right calf muscle length was measured with subjects facing a wall in the step-stance position. They performed a forward lunge by bending the front (left) knee towards the wall and keeping the right heel in contact with the floor, stretching the right calf muscle. The angle from vertical was measured with the inclinometer placed along the midline of the Achilles tendon. The test was performed three times with the median used for analysis.

\section{Hip muscle strength}

A Nicholas manual muscle tester (NMMT) (Lafayette, Indiana, USA) was used to measure isometric strength of hip flexors, adductors, abductors, and rotators. This device has been found to be reliable in measuring muscle strength in elementary school aged children. ${ }^{9}$ For all measurements, the tester placed the NMMT on the subject's limb and applied a gradual force over one second, with the subject manually resisting the force. The tester then 
Table 2 Descriptive information for dancers $(n=53)$ and controls $(n=40)$, at baseline and final (12 months) visit given as the mean (SD)

\begin{tabular}{|c|c|c|c|c|}
\hline \multirow[b]{2}{*}{ Characteristic } & \multicolumn{2}{|c|}{ Baseline (0 months) } & \multicolumn{2}{|c|}{ Final (12 months) } \\
\hline & Dancers & Controls & Dancers & Controls \\
\hline Age (years) & $9.6(0.8)$ & $9.6(0.7)$ & $10.7(0.8)$ & $10.6(0.7)$ \\
\hline Height $(\mathrm{cm})$ & $136.2(6.7)$ & $138.2(7.6)$ & $143.0(7.6)$ & $144.9(7.8)$ \\
\hline Weight (kg) & $30.3(5.3)^{\star}$ & $33.8(6.3)$ & $34.4(6.2)^{\star}$ & $39.2(7.5)$ \\
\hline $\mathrm{BMI}\left(\mathrm{kg} / \mathrm{m}^{2}\right) \dagger$ & $16.3(2.2)^{\star}$ & $17.6(2.7)$ & $16.7(2.0)^{\star}$ & $18.6(2.8)$ \\
\hline Hours/week sport $\ddagger$ & $2.8(2.2)$ & $1.5(0.9)$ & $2.6(1.8)$ & $1.8(1.2)$ \\
\hline Tanner stage $1 \Phi$ & $48(91 \%)$ & $22(55 \%)$ & $27(51 \%)$ & $1(25 \%)$ \\
\hline Tanner stage $2-4 \rrbracket$ & $5(9 \%)^{\star}$ & $18(45 \%)$ & $26(49 \%)$ & $30(75 \%)$ \\
\hline
\end{tabular}

* Significant difference from controls $(\mathrm{p}<0.01)$.

†BMI, body mass index $=$ weight $(\mathrm{kg}) /(\text { height }(\mathrm{m}))^{2}$.

¥Current extracurricular sport (hours/week).

\Defined by self-reported Tanner breast staging where 1 indicates prepubertal and $2-4$ indicates peripubertal. Figures given as the number $(\%)$

applied additional force until the muscle contraction broke and the limb began to move. For the measurement of hip flexor and rotator strength, the subject was in a sitting position, whereas for adductor and abductor strength the subject lay supine. The test was carried out three times, and the maximal value used in analysis.

\section{STATISTICAL ANALYSIS}

Comparisons between baseline and final and between dancers and controls were made using two way analysis of variance (time $\times$ group), with time being a repeated factor. Post hoc tests were used to locate significant differences. To adjust for the effect of weight on strength measurements, all raw strength data were divided by the subject's weight at that time point. The relation between the baseline level and the amount of change over the 12 months for each variable as well as the relation between the change in hip ER and IR strength and hip ER and IR range were sought using Pearson's $r$ correlations. A significance level of $\mathrm{p}<0.05$ was set.

\section{Results}

Table 3 presents results for baseline and final hip and ankle range of motion in dancers and controls. Dancers and controls had similar baseline hip ER range and increased their range to a similar extent, about $8-12^{\circ}$. There was no relation between the change in hip ER range and the change in hip external rotator muscle strength $(r=0.13, \mathrm{p}>0.05)$. Dancers

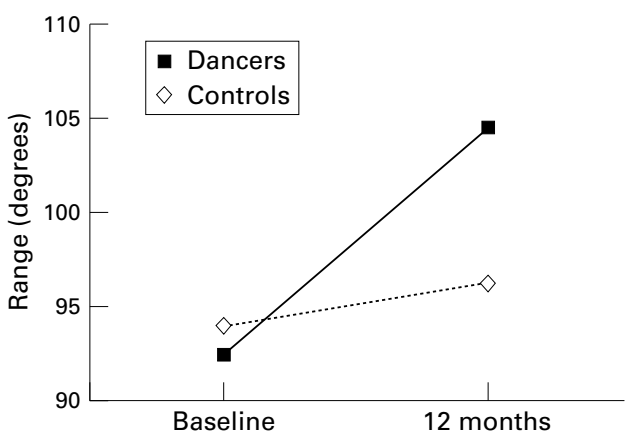

Figure 1 Mean baseline and 12 month range of total hip turnout in dancers and controls.

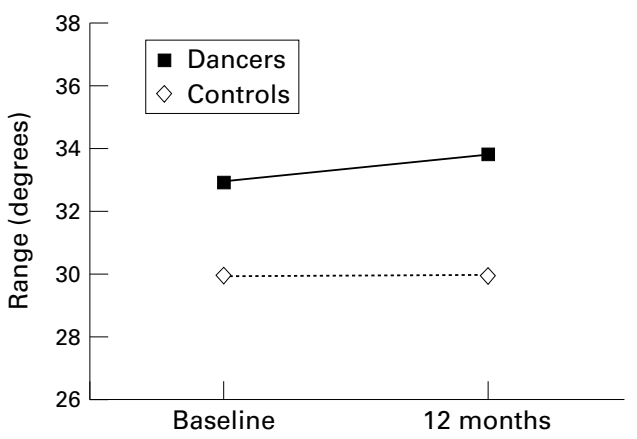

Figure 2 Mean baseline and 12 month range of ankle dorsiflexion in dancers and controls.

started with less hip IR than controls but showed significant increases in range with an average of $12^{\circ}$ whereas controls did not change. Therefore at the 12 month follow up, the two groups had similar values. Those with greater increases in hip internal rotator muscle strength showed greater increases in hip IR range $(r=0.34, \mathrm{p}<0.001)$. The ratio of hip ER:IR was greater in dancers than controls at baseline. Dancers displayed an average decrease in this ratio whereas controls showed an increase such that by the 12 months the ratios were similar in the two groups.

Left and right as well as total hip turnout was the same in dancers and controls at baseline (fig 1). However, after 12 months, dancers significantly increased their total and right turnout with a trend to increase on the left whereas controls did not change. There was a mean $12^{\circ}$ increase in total turnout in the danc-

Table 3 Baseline and final measurements of range of motion together with differences for dancers and controls, given as mean (SD)

\begin{tabular}{|c|c|c|c|c|c|c|}
\hline \multirow[b]{2}{*}{ Variable } & \multicolumn{2}{|l|}{ Baseline } & \multicolumn{2}{|l|}{ Final } & \multicolumn{2}{|l|}{ Difference } \\
\hline & Dancers & Controls & Dancers & Controls & Dancers & Controls \\
\hline \multicolumn{7}{|l|}{ Hip rotation $\left(^{\circ}\right)$} \\
\hline Internal & $26.9(14.5)^{\star \star}$ & $35.8(8.5)$ & $39.0(11.5)$ & $37.2(11.6)$ & $12.5(13.5) \dagger^{\star \star}$ & $0.5(13.9)$ \\
\hline External & $33.3(12.3)$ & $36.7(10.2)$ & $45.0(12.2)$ & $47.2(9.6)$ & $11.7(11.3) \dagger$ & $8.1(17.6) \dagger$ \\
\hline ER:IR & $1.5(0.9)^{\star}$ & $1.1(0.4)$ & $1.2(0.5)$ & $1.5(1.4)$ & $-0.3(0.9)$ & $0.5(1.2)$ \\
\hline Non-hip ER $\left(^{\circ}\right)$ & $12.4(11.2)$ & $10.5(11.9)$ & $7.8(13.9)$ & $3.6(15.6)$ & $-4.6(12.6) \dagger$ & $-7.0(18.4) \dagger$ \\
\hline \multicolumn{7}{|l|}{ Turnout $\left({ }^{\circ}\right)$} \\
\hline Right & $45.6(10.2)$ & $47.2(9.3)$ & $52.8(7.2)^{\star}$ & $48.4(10.0)$ & $7.2(9.8) \dagger^{\star \star}$ & $1.1(11.2)$ \\
\hline Left & $46.9(9.6)$ & $46.9(8.4)$ & $51.7(6.4)$ & $48.0(8.8)$ & $4.3(8.4)$ & $1.1(9.9)$ \\
\hline Total & $92.5(19.2)$ & $94.1(16.8)$ & $104.5(12.7)^{\star \star}$ & $96.3(17.9)$ & $12.0(16.7) \dagger^{\star \star}$ & $2.2(20.0)$ \\
\hline Ankle DF $\left(^{\circ}\right)$ & $32.9(6.0)$ & $29.9(6.4)$ & $33.8(6.2)$ & $30.0(7.2)$ & $0.9(5.4)$ & $0.1(7.3)$ \\
\hline Calf length $\left({ }^{\circ}\right)$ & $25.3(8.6)$ & $26.1(9.0)$ & $28.8(7.2)$ & $27.7(8.8)$ & $3.5(7.2) \dagger$ & $1.6(9.9) \dagger$ \\
\hline
\end{tabular}

Non-hip ER = turnout in standing of right leg - supine ER of right leg.

$\star$ Significant difference from controls $(\mathrm{p}<0.05)$.

$\star \star$ Significant difference from controls $(\mathrm{p}<0.01)$.

+ Significant difference from baseline $(\mathrm{p}<0.01)$

$\mathrm{ER}$, external rotation; IR, internal rotation; DF, dorsiflexion. 


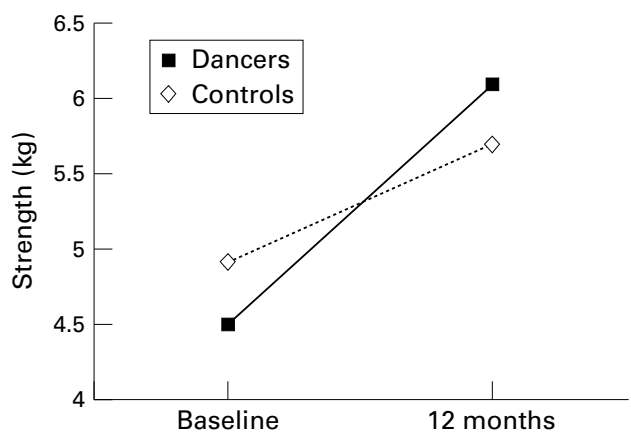

Figure 3 Mean baseline and 12 month strength of hip abductors in dancers and controls.

ers. The measure of ER achieved from joints other than the hip during right turnout, non-hip ER (calculated by subtracting right hip ER from right hip turnout), was similar in the two groups at baseline and showed similar reductions over the 12 months, indicating that more of the turnout position was achieved from the hip and less from the knees and ankle/foot joints.

Calf length was similar between groups at baseline and at 12 months with a small but significant increase over this time. Ankle DF was also similar at baseline and 12 months in dancers and controls but did not change significantly over time (fig 2 ).

Table 4 presents results for baseline and final hip muscle strength for dancers and controls. Both groups showed significant increases in strength over the 12 month period in all hip muscles tested when adjusted for body weight. Dancers and controls were found to have similar hip adduction and abduction strength at baseline but dancers had significantly greater strength increases in these muscles over the 12 months. This meant that the dancers had stronger hip adductors and abductors at the final measurement (fig 3). Although dancers had significantly weaker hip external rotators than controls at baseline, they had greater increases in strength and were stronger than controls at the 12 month time point (fig 4). Conversely, hip internal rotator strength was similar in both groups at baseline and at follow up, indicating that both displayed similar strength increases over time. Hip flexion strength also changed similarly between the two groups over the 12 months.

All of the variables showed a significant negative relation between the baseline level and the amount of change over the 12 months (all

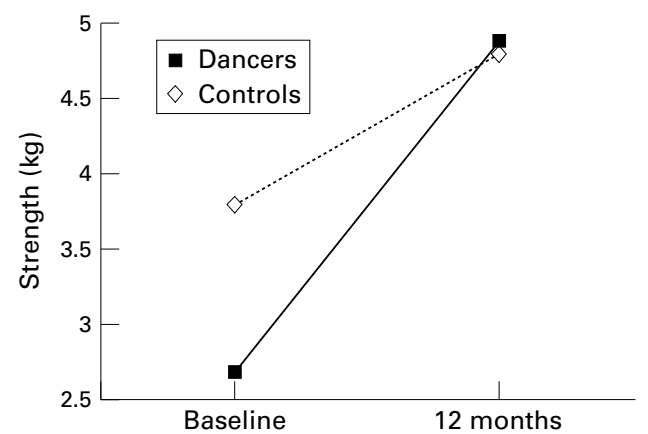

Figure 4 Mean baseline and 12 month strength of hip external rotators in dancers and controls.

$\mathrm{p}<0.001)$. Those with less range of hip and ankle motion and less muscle strength initially achieved greater increases than those with higher baseline values. The individual Pearson $r$ correlations between initial range and change in range of motion were: hip IR $=-0.62$; hip $\mathrm{ER}=-0.52 ;$ left, right, and total turnout all = -0.64 ; DF $=-0.40$. For hip muscle strength, the correlations were: flexion $=-0.33$; $\mathrm{ER}=$ -0.54 ; IR $=-0.50$; abduction $=-0.64$; adduction $=-0.75$.

\section{Discussion}

We begin by emphasising that physical activity, such as ballet training, has been shown to have health benefits ${ }^{10}$ and therefore is likely to benefit children who participate, irrespective of whether they will continue into a professional career. Ballet teaches posture, musicality, rhythm, and may improve bone and cardiovascular health. ${ }^{11}$ Thus, a dancer with limited turnout may still benefit enormously from balletic training. Nevertheless, it is important to define physiological limitations, when they exist, so that children and teachers alike may set realistic goals.

HIP ROTATION RANGE OF MOTION

Both dancers and controls gained significant hip ER during 12 months. This result was mirrored in total turnout as could be expected. These data argue against a ballet specific training effect at this age. That hip IR, a movement not trained in ballet, also improved in both groups provides further evidence against a training effect. Increases in active range of motion at this age are likely to be due to increases in strength, as passive joint range of motion generally remains stable at this age. ${ }^{12}$

Table 4 Baseline and final measurements of strength ( $\mathrm{kg}$ ), with differences, in all dancers and controls, given as mean (SD)

\begin{tabular}{|c|c|c|c|c|c|c|}
\hline \multirow[b]{2}{*}{ Muscle group } & \multicolumn{2}{|l|}{ Baseline } & \multicolumn{2}{|l|}{ Final } & \multicolumn{2}{|l|}{ Difference } \\
\hline & Dancers & Control & Dancers & Control & Dancers & Control \\
\hline Hip flexors & $8.3(2.0)$ & $9.3(2.0)$ & $11.7(3.3)$ & $12.6(3.9)$ & $3.4(3.2) \dagger$ & $3.3(4.3) \dagger$ \\
\hline Hip internal rotators & $3.1(1.6)$ & $4.2(1.3)$ & $5.4(1.7)$ & $5.6(1.8)$ & $2.3(1.8) \dagger^{\star}$ & $1.4(1.9) \dagger$ \\
\hline Hip external rotators & $2.7(0.8)^{\star \star}$ & $3.8(1.3)$ & $4.9(1.5)^{\star}$ & $4.8(1.8)$ & $2.2(1.5) \dagger^{\star \star}$ & $1.0(2.2) \dagger$ \\
\hline Hip abductors & $4.5(1.4)$ & $4.9(1.8)$ & $6.1(1.7)^{\star \star}$ & $5.7(1.9)$ & $1.6(2.1) \dagger^{\star}$ & $0.8(2.5) \dagger$ \\
\hline Hip adductors & $4.2(1.6)$ & $5.2(1.7)$ & $6.5(1.5)^{\star \star}$ & $5.5(1.7)$ & $2.3(2.1) \dagger^{\star \star}$ & $0.3(2.6) \dagger$ \\
\hline
\end{tabular}

Statistics were conducted on measurements divided by corresponding subject body weight.

tSignificant difference from baseline $(\mathrm{p}<0.001)$.

$\star$ Significant difference from controls $(\mathrm{p}<0.05)$

$\star \star$ Significant difference from controls $(\mathrm{p}<0.01)$. 
Indeed, there was a significant relation between increased active hip IR range and strength of hip internal rotators.

Of interest, but not unexpected, was the finding that non-hip ER decreased in both dancers and controls. We remind the reader that non-hip ER, a value derived by subtracting hip ER (measured by goniometer) from turnout (measured by turnout board), is a non-physiological movement-it represents external rotation at the knee, ankle, and even midtarsal joints. When subjects are measured cross sectionally, non-hip ER includes a measure of tibial torsion, but skeletal rotation would contribute very little, if anything, to change in this measure over 12 months. Thus our findings of reduced non-hip ER are consistent with the physiological loss of soft tissue suppleness that accompanies maturation in boys and girls of this age. Simply put, the children can no longer "screw" their knees and ankles into as much ER as they could a year earlier. We note that although the difference did not reach statistical significance in this population, there was a trend for controls to lose more non-hip ER than the dancers.

STRENGTH CHANGES

Of interest was the finding that strength increases occurred preferentially in ballet dancers in muscle groups specifically trained in ballet. Strength of hip external rotators, abductors, and adductors all increased significantly more in dancers than controls. Hip external rotators and abductors are important prime movers for both turnout and hip abduction and elevation movements that are fundamental to the female dancer's art. Hip adductors are used to control the leg as it returns from these movements and to stabilise the pelvis during one leg manoeuvres. Dancers also use the adductors to help with maximal turnout in certain degrees of hip rotation. ${ }^{13}$ Consistent with a training effect is the finding of no differences in change of strength between dancers and controls for muscle groups not specifically trained in ballet - for example, hip flexion, hip IR.

ANKLE DF RANGE OF MOTION

An important finding was that ankle DF, measured in the parallel position, did not improve in dancers compared with controls and it changed only minimally in both groups. This indicates that ankle DF, and by inference, plié, appears not to be amenable to training at this age. Although this would be a surprising finding for some ballet instructors, it was one of our predictions. Our cross sectional study of junior elite ballet dancers showed that their mean range of ankle DF was no different from physiotherapy student controls ${ }^{14}$ despite the dancers' years of balletic training. Our longitudinal study of that population also showed no change in DF across a 12 month period. ${ }^{15}$ Furthermore, the absolute degrees of ankle DF in our 8-11 year old dancers at baseline was very similar to that of the highly trained junior elite dancers. ${ }^{14}$ Taken together, these data provide convincing evidence that ankle DF appears largely fixed even at age 8-11 years in girls. This would be consistent with it being limited by bone-bone apposition (tibiotalar) rather than soft tissue.

A clinical implication of this finding is that dance teachers should not attempt to "improve" a dancer's plié to a large degree, even if it is less than that of her classmates. It is theoretically possible that forcing plié may predispose to the clinical condition of anterior impingement, ${ }^{6}$ but there are as yet no data showing any association between ankle range of motion and injury. However, there was a negative relation between baseline range of ankle $\mathrm{DF}$ and the change in DF over the 12 months. Although this could represent the statistical phenomenon of regression to the mean, it may be that small increases in range can be achieved with stretching in those whose range is initially restricted.

In summary:

(1) Even at this young age, mild active muscle loading can result in strength gains. Given that the girls in this study did not undertake many hours of ballet a week, this finding should be generalisable to a general population of children.

(2) Range of motion at the hip appears to be increasing at this age, which may be related to gains in active hip strength.

(3) Ankle DF is largely fixed at this age, and ballet teachers should ensure that range of motion is maintained, but forcing plié should be discouraged as this may be associated with increased risk of injury.

(4) The balletic population provides an opportunity for paediatric researchers to better understand both the scope and limits of girls in this age group. Although our findings will be of particular interest and applicability to those working with the many thousands of young ballet dancers, some of our results may be generalisable to a larger population of girls.

The authors thank the girls and their parents/guardians for their participation. The study was supported by grants from the National Health and Medical Research Council (project grant no 980662), the H\&L Hecht Trust, and the Estate of Daniel Scott.

1 Hamilton W. Physical prerequisites for ballet dancers. fournal of Musculoskeletal Medicine 1986;3:61-6.

2 Hamilton WG, Hamilton LH, Marshall P, et al. Profile of the musculoskeletal characteristics of elite professional ballet dancers. Am $\mathcal{F}$ Sports Med 1992;20:267-73.

3 Wiesler E, Hunter M, Martin D, et al. Ankle flexibility and injury patterns in dancers. Am $\mathcal{F}$ Sports Med 1996;24:7547 .

4 Kirkendall D, Calabrese L. Physiological aspects of dance. Clin Sports Med 1983;2:525-37.

5 Reid DC, Burnham RS, Saboe LA, et al. Lower extremity flexibility patterns in classical ballet dancers and their correlation to lateral hip and knee injuries. Am $\mathcal{F}$ Sports Med 1987; 15:347-52

6 Khan K, Brown J, Way S, et al. Overuse injuries in classical ballet. Sports Med 1995;19:341-57.

7 Bennell K, Khan K, Matthews B, et al. Hip and ankle range of motion and hip muscle strength in young novice female ballet dancers and controls. Br F Sports Med 1999;33:340-

8 Morris $\mathrm{N}$, Udry J. Validation of a self-administered instrument to assess stage of adolescent development. Fournal of Youth and Adolescence 1980;9:271-80.

9 Horvat M, McManis B, Seagraves F. Reliability and objectivity of the Nicholas Manual Muscle Tester with objectivity of the Nicholas Manual Muscle Tester with
children. Isokinetics and Exercise Science 1992;2:175-81.

10 Freedson P. Physical activity among children and youth. Canadian fournal of Sport Sciences 1992;17:280-3.

11 Bennell K, Khan K, Matthews B, et al. Activity-associated differences in bone mineral are evident before puberty: a 
cross-sectional study of 130 female novice dancers and controls. Pediatric Exercise Science 2000:12;371-81.

12 Staheli L. Fundamentals of pediatric orthopedics. New York: Raven Press, 1992.

13 Trepman E, Gellman R, Solomon R, et al. Electromyographic analysis of standing posture and demi-plié in balle and modern dancers. Med Sci Sports Exerc 1994;26:77182.

\section{Take home message}

- Muscle strength of the hip external rotators and abductors is important for achieving correct turnout in ballet

- Forcing plié is to be discouraged as range of ankle dorsiflexion is largely fixed

- Hip range of motion and hip muscle strength appear to be increasing in girls aged 8-11 years
14 Khan K, Roberts P, Nattrass C, et al. Hip and ankle range of motion in elite classical ballet dancers and controls. Clin $\mathcal{F}$ Sport Med 1997;7:174-9.

15 Khan K, Bennell K, Ng S, et al. Can 16-18 year-old elite ballet dancers improve their hip and ankle range of motion over a 12 month period? Clin f Sport Med 2000;10:98-103. 